\title{
Fundamentals of property and compositions management concrete mix and concrete
}

\author{
Bakhridin Khasanov $^{1 *}$, Ruzimurot Choriev ${ }^{1}$, Nikolai Vatin $^{2}$, Zukhra Ismailova ${ }^{1}$, \\ Alisher Tillaev ${ }^{3}$, and Timur Mirzaev ${ }^{4}$ \\ ${ }^{1}$ Tashkent Institute of Irrigation and Agricultural Mechanization Engineers, Tashkent, Uzbekistan \\ ${ }^{2}$ Peter the Great St.Petersburg polytechnic university, St.Petersburg, Russia \\ ${ }^{3}$ Academic Lyceum "International House Tashkent", Tashkent Institute of Irrigation and Agricultural \\ Mechanization Engineers, Tashkent, Uzbekistan \\ ${ }^{4}$ YEOJU Technical Institute in Tashkent, Tashkent, Uzbekistan
}

\begin{abstract}
The choice of the concrete composition following the set research tasks must satisfy the following requirements: 1-the maximum achievable strength on the given starting materials; 2-the required formability, corresponding to the accepted vibration-impact-peristaltic pressing; 3-a given level of dehydration of the concrete mixture, providing a residual $W / C$, close to the normal density of the cement paste. The accepted conditions are necessary and sufficient when using the physicalanalytical method of designing concrete composition. Distinctive features of the method are the use of a large amount of information and the absence of arbitrary coefficients, technological constants, or parameters. The necessary data for the assignment of concrete compositions are determined according to the data of preliminary laboratory experiments, the given technological parameters of mechanisms and equipment, and the design characteristics of concrete and the structure to be formed. For the experimental study, a total of six independent information streams of initial data are used: 1-physical and mechanical properties of the constituents of concrete $\left(R_{c}, \rho_{c}, \rho_{c}^{\circ},[V / C], p_{c}, \gamma_{3}, \rho_{\text {shch }}, \gamma_{s h}, \gamma_{s h c h}{ }^{\circ}\right)$; 2-laboratory data of tests of raw materials in concrete mix and concrete (a, b, c, Ku, A, B); 3design characteristics of concrete mix and concrete $\left(R_{b}, F, W, O K, Z_{h}\right) ; 4$ characteristics of the product to be concreted $(V, h, l, \mu) ; 5$-technological characteristics of equipment, mechanisms, and devices (th, $t b, T O, t 0) ; 6-$ the cost per unit volume of raw materials ( $\mathrm{Sc}, \mathrm{Cn}, \mathrm{Ssh}, \mathrm{Se}, \mathrm{Sg}$ ). Obviously, the listed volume of initial information comprehensively characterizes the materials used and the conditions for forming the product. The previously developed technological conditions for forming concrete pipes, in addition to the above, require, when assigning the composition of concrete, to take into account the observance of the balance of masses in the concrete mixture and compacted, modified concrete. This should be manifested in checking the equation of absolute volumes for the original and compacted (dewatered) concrete.
\end{abstract}

*corresponding author: mr.bakhridin@mail.ru 


\section{Introduction}

The greatest difficulty is the choice of the initial water-cement ratio. It would seem that the $V / C$ value should be taken equal to the $[V / C]$ value for the test of normal density[1-10]. This is the condition for obtaining the maximum strength of concrete [11-15]. However, the formability of such an inactive, semi-dry concrete mixture is significantly impaired. In addition, when water is squeezed out and possible under-compaction, a drop in strength is likely. Therefore, it is necessary to comply with the condition of the mutual consistency of two opposite requirements:

- decrease in $V / C$ to ensure $R_{\max }$;

- increase in $W / C$ at a given cement consumption to ensure the rheological properties of the compacted mixture and optimal conditions for the structure formation of concrete.

The relationship between the above two opposite conditions is shown in Figure 1. The water-cement ratio of concrete is determined based on the limiting water-holding capacity of the cement paste, investigated by I.N. Akhverdov [16-22], the interval of variation of the optimal water-cement ratio is in the range from $(V / C) \min$ to $(V / C) \max$. When the value $(V / C)$ min, determined according to [23], the value of the coefficient $C_{o p t}=0.876 \cdot[\mathrm{V} / \mathrm{C}]$. The ultimate water-holding capacity is measured from the point of the greatest strength of the cement stone, equal to $1.65 \cdot[\mathrm{V} / \mathrm{C}]$. Therefore, $(V / C)$ max is equal to:

$(V / C) \max =1.65 \cdot \mathrm{Copt}=1.65 \cdot 0.876[\mathrm{~V} / \mathrm{C}]=1.44 \cdot[\mathrm{V} / \mathrm{C}]$

In the experiments, the portland cement of the Akhangaran plant M400 with $[V / C]=$ $0.24 \ldots 0.25$ was used. Therefore, $(V / C)$ max is equal to $0.34 \ldots 0.36$.

Determination of the optimal water-cement ratio in hypersolid concrete $\left(\varepsilon_{\text {opr }}=6.0 \%\right)$

Explanation by the picture:

Left side: concrete strength scale.

Right side: scale of deformability of cement paste

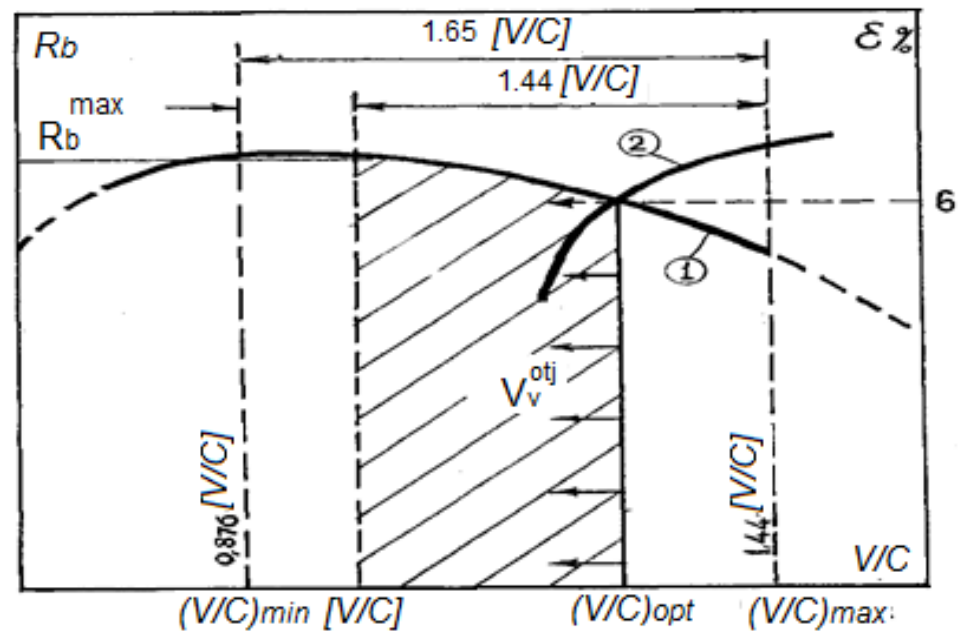

1 is the curve of changes in the strength of concrete; 2 is the compression curve of the cement paste.

\section{Methods}

Following the methodology for designing concrete compositions [24, 25], three characteristics of the consistency of the concrete mixture are calculated:

1. Indicator of hardness of concrete mix: 


$$
G=1-O K / O K_{p r} \text { or } G=\lg Z h / Z h_{\mathrm{o}}
$$

where $O K_{p r}, Z h_{0}$ are the limiting values of the cone settlement and the conditional stiffness of the concrete mixture of the highest mobility $\left(O K_{p r}=20 \mathrm{~cm}, Z h_{0}=0.62 \mathrm{~s}\right)$.

1. The limiting index of stiffness, equal to

$$
[G]=G+\mathrm{c} \cdot Z
$$

where $\mathrm{c}$ is the cement qualimeter

1. Coefficient of concrete mix mobility:

$$
m=1 /(1+G)
$$

The methodology for designing concrete compositions, adopted in [24, 25], involves the use of three dependencies: the Bolomey equations $\left(R_{b}=f(C / V)\right)$, the equations of absolute volumes $\left(V_{b}=\Sigma V k\right)$ and the equations of workability of the concrete mixture $(G=f(X, Y, Z))$.

In our case, at $V / C=$ const, two equations remain for determining the four unknown concrete compositions $(C, V, P, S h c h)$. Therefore, the following method of appointment and optimization of the initial composition of concrete is adopted.

1. We set the sand-cement ratio

$$
x=P / C
$$

taking it, for example, equal to $\mathrm{x}=0.6$.

2. The saturation of concrete with sand is calculated

$$
X=\frac{\chi}{1 / \rho_{u}^{0}+V / C}
$$

where $p_{c}{ }^{\circ}$ is the density of the hydrated cement particles.

3. Determined the saturation of concrete with crushed stone

$$
Y=\frac{[G]-a \cdot X}{\mathrm{~B}}
$$

where a is the sand qualimeter; $c$ - crushed stone qualimeter.

4. Calculate the maximum bulk volume of crushed stone in concrete

$$
V_{0}=\frac{Y}{m+Y}
$$

where $m$ is the mobility coefficient of the concrete mixture.

5. Determine the volume of the solution in concrete, assuming the limiting value of the compaction of the concrete mixture $\left(V_{b}=10001\right)$

$$
V_{p}=1000-V_{0} \cdot \frac{\gamma_{\text {shch }}^{\circ}}{\rho_{\text {shch }}}
$$

where $\gamma_{\text {shch }}^{\circ}$ is bulk density of crushed stone in a compacted state; $\rho_{\text {shch }}$ is the density of crushed stone.

6. The output of cement-sand mortar from one $\mathrm{kg}$ of cement is found by the formula: 


$$
\varphi_{p}=\frac{1}{\rho_{c}^{\circ}}+\frac{V}{C}+\frac{x}{\rho_{c}}
$$

where $\rho_{c}{ }^{\circ}$ is the density of hydrated cement particles; $\rho_{p}$ is the density of sand particles.

7. We calculate the consumption of materials for $1 \mathrm{~m}^{3}$ of concrete

$$
\begin{aligned}
& \mathrm{C}=V_{p} / \varphi_{p} \\
& V=C \cdot V / C \\
& P=C \cdot \mathrm{x} \\
& \text { Shch }=V_{0} \cdot \gamma_{\text {shch }}{ }^{\circ}
\end{aligned}
$$

8. Let's calculate the calculated average concrete density

$$
\gamma_{b}=C+V+P+S h c h
$$

The above calculations were performed in tabular form (Table 1), taking variable values of $\mathrm{x}$ with a step of 0.1 .

\section{Results and Discussion}

Considering the curve of the change in the strength of concrete (Figure 1) in combination with the compression curve of the deformation of the cement paste as a function of the $V / C$ values, we find that the optimal value $(V / C)$ opt should be $9 \ldots 12 \%$ less $(V / C)$ max, composing for used cements:

$$
\begin{gathered}
(V / C) \text { opt }=0.31 \ldots 0.32 \\
(V / C) \text { opt }=0.32=\text { const }=1.28 \cdot[V / C]
\end{gathered}
$$

It should be noted that the presented curve $R_{b}$ is built for concrete without chemical additives. This is caused by a decrease in their efficiency when squeezing water. The value $(V / C)$ opt was chosen in such a way that, as a result of removing $15 \ldots 18 \%$ of mixing water, the value of $V / C$ in the pressed concrete was created, close to the water-cement factor of the test of normal density. In this case, sufficient deformability of concrete and its maximum possible strength is ensured.

The assigned $W / C$ value allows you to calculate the dilution of the cement paste in the concrete mixture using the formula

$$
Z=1 /[V / C]=1 / V / C
$$

where $[V / C]$ is the water-cement ratio of the cement paste of normal density.

Obviously, the dilution of the cement paste is proportional to the difference between the cement-water ratios of the normal density paste and the concrete mixture.

For the production conditions of the Kuylyuk plant MZhBK, the calculation of equivalent concrete compositions was made. The initial data for the design of concrete compositions were obtained by testing the initial materials and experimental studies of the concrete mixture and concrete.

We accept the composition of concrete № 7 (Table 1) with the minimum consumption of cement and the highest density $\left(\gamma_{b}=2427 \mathrm{~kg} / \mathrm{m}^{3}\right)$. The nominal composition of the accepted concrete mixture is 1: $0.85: 2.89$ at $W / C=0.32$. We check the accepted composition of the concrete mixture for density (mass balance) after squeezing $15 \ldots 18 \%$ of the amount of mixing water $\left(V_{\text {ost }}=131 \ldots 126 \mathrm{l} / \mathrm{m}^{3}\right)$.

We check the balance of masses from the equation of absolute volumes, taking into 
account $6 \%$ of the crimping of the cement paste in molded concrete $\left(\varepsilon=\frac{\Delta C}{C+\Delta C}\right)$ with a pipe wall thickness of $150 \mathrm{~mm}$ :

$$
V_{c}^{o c t}+V_{v}^{o c t} \approx V_{T}^{o p r}
$$

Table 1. Calculation table of equivalent concrete compositions

\begin{tabular}{|c|c|c|c|c|c|c|c|c|c|c|c|}
\hline $\begin{array}{c}\text { № of } \\
\text { formulations }\end{array}$ & \multirow{2}{*}{$\mathrm{x}$} & $\mathrm{X}$ & $Y$ & $V_{0}$ & $V_{p}$ & $\varphi_{p}$ & $C$ & $V$ & $P$ & $\mathrm{Shch}$ & $\gamma_{b}$ \\
\hline & & & & $\mathrm{m}^{3}$ & $\mathrm{~m}^{3}$ & $\mathrm{dm}^{3} / \mathrm{kg}$ & $\mathrm{kg} / \mathrm{m}^{3}$ & $\mathrm{~kg} / \mathrm{m}^{3}$ & $\mathrm{~kg} / \mathrm{m}^{3}$ & $\mathrm{~kg} / \mathrm{m}^{3}$ & $\mathrm{~kg} / \mathrm{m}^{3}$ \\
\hline 1 & 0.6 & 0.88 & 3.48 & 0.88 & 450 & 0.91 & 485 & 158 & 297 & 1469 & 241 \\
\hline 2 & 0.7 & 1.02 & 3.0 & 0.87 & 460 & 0.95 & 484 & 155 & 339 & 1442 & 242 \\
\hline 3 & 0.8 & 1.17 & 2.52 & 0.85 & 473 & 0.98 & 483 & 154 & 386 & 1407 & 243 \\
\hline 4 & 0.9 & 1.31 & 2.04 & 0.82 & 491 & 1.02 & 481 & 154 & 433 & 1358 & 242 \\
\hline 5 & 1.0 & 1.46 & 1.56 & 0.78 & 518 & 1.06 & 489 & 156 & 489 & 1287 & 242 \\
\hline 6 & 1.1 & 1.61 & 1.08 & 0.71 & 561 & 1.10 & 510 & 163 & 561 & 1171 & 240 \\
\hline \multicolumn{10}{|c|}{ Optimal concrete composition } \\
\hline per & 0.85 & 1.24 & 2.28 & 0.83 & 481 & 1.0 & 480 & 154 & 408 & 1385 & 242 \\
\hline
\end{tabular}

Substituting the calculated data from Table 1, we find, taking the smallest percentage of water extraction $15 \%$

$$
480(1-0.02) / 2.74+154(1-0.15)=480 / 2.74+154(1-0.18) \text { or } 301 l=301 l
$$

As can be seen from the test, the condition for maintaining the density of the concrete structure is met.

It should be noted that a certain amount of the gas phase still remains in the pressurized volume. According to petrographic studies of the structure of pressed concrete, its amount is less than $0.6 \%$ of the volume. In ordinary vibro-compacted concrete, the residual volume of the gas phase, according to L.A. Malinina [26], is $2 \ldots 4 \%$, which is $4 \ldots 7$ times higher than the residual gas phase in concrete pipes. We observed the same volume of the gas phase in comparative petrographic studies of conventional concretes.

Frost's resistance of concrete in the appointment of its composition is produced using GOST 10060-87.

The compositions of concrete of a given frost resistance were determined using the value of the "compensation factor $\Phi_{k}$ ", which is equal to the ratio of the sum of volumes of air and contraction pores to the volume of free water content of concrete (volume of ice content of concrete).

The structural characteristic of concrete frost resistance is calculated by the formula

$$
\Phi=\left(V_{B}+V_{K}\right) / V_{L}
$$

where $V_{B}$ is the volume of air or gas in the compacted mixture, $\% ; V_{K}$ is volume of contraction pores in concrete, $\% ; V_{L}$ is the volume of free water in concrete that freezes at $20^{\circ} \mathrm{C}$.

According to the normative data given in GOST 10060-87, the value of the compensation factor can be expressed as a function of the frost resistance of concrete, with an error of $<4 \%$

$$
\Phi_{k}^{n o r m}=\Phi_{0} \cdot[1-\exp (-5 F / 100)]
$$

where $\Phi_{0}=1.4$ is the limiting compensation factor of concrete without additives;

$\mathrm{F}$ is design grade of concrete for frost resistance in cycles (from F50 to F500). 
The calculation results are given in table. 2 .

Table 2. Dependence of the compensation factor on the concrete grade of the given frost resistance

\begin{tabular}{|c|c|c|c|}
\hline \multirow{2}{*}{$\begin{array}{l}\text { Design grade of } \\
\text { concrete for frost } \\
\text { resistance, in cycles }\end{array}$} & \multicolumn{3}{|c|}{ Compensation factor $\Phi_{k}$, not lower } \\
\hline & $\begin{array}{c}\text { according to GOST } \\
10060-87\end{array}$ & $\begin{array}{l}\text { according to the } \\
\text { formula (4.17) }\end{array}$ & deviation \\
\hline 50 & 0.35 & 0.31 & +0.04 \\
\hline 75 & 0.45 & 0.44 & +0.01 \\
\hline 100 & 0.55 & 0.55 & - \\
\hline 150 & 0.70 & 0.74 & -0.04 \\
\hline 200 & 0.85 & 0.88 & -0.03 \\
\hline 300 & 1.05 & 1.09 & -0.04 \\
\hline 400 & 1.20 & 1.21 & -0.01 \\
\hline 500 & 1.30 & 1.29 & +0.01 \\
\hline
\end{tabular}

Based on the formulas given in GOST 10060-87, the condition for ensuring the specified frost resistance of concrete is observed if the actual compensation factor of concrete is greater than that required for the design value of frost resistance. The actual compensation factor of concrete is:

$$
\Phi_{k}=\left(10 v+0.12 C / \rho_{c}\right) / C(V / C-0.27)
$$

The required value of the compensation factor of concrete of a given frost resistance depends on the consumption of cement $C$, a change in the value of the $V / C$ factor, as well as a change in the air entrainment of concrete $V_{b}$ due to the use of special chemical additives.

The design of the composition of concrete of given frost resistance is carried out in the following order:

If necessary, the conditions of frost resistance of concrete should consider the change in $W / C$ as a result of water extraction.

1. The value of the $V / C$ factor is determined from the condition of ensuring the design strength of concrete;

2. For a given frost resistance, the required compensation factor of concrete is calculated using the formula (17), table. 2.

3. The maximum permissible consumption of cement for concrete of a given frost resistance at the found value of $\mathrm{W} / \mathrm{C}$ is calculated using the formula (18)

$$
C_{\text {max }}=\frac{10 V_{\mathrm{B}}}{\Phi_{k}^{\text {actions }}\left(\frac{V}{C}-0.27\right)-0.12 \cdot C / \rho_{c}}
$$

4. The resulting cement consumption $C_{\max }$ is compared with the minimum required cement consumption $C_{\min }$ based on the conditions for ensuring the density of hydraulic concrete $\left(C_{\min }=210 \mathrm{~kg} / \mathrm{m}^{3}\right)$, or with the minimum cement consumption required to ensure the specified mobility of the concrete mixture.

5. A new value of $W / C$ is calculated according to the given value of $\Phi_{\kappa}$ and the accepted minimum required cement consumption $\mathrm{Cmin}$ from the condition of ensuring the workability of concrete.

$$
\frac{V}{C}=0.27+\frac{1}{\Phi_{k}}\left(\frac{10 \cdot V_{\mathrm{B}}}{C_{\min }}+\frac{0.12 C}{\rho_{C}}\right)
$$

This $W / C$ value is compared with the residual $W / C$ value of concrete. 


$$
\Phi_{k}^{\text {action }}=\frac{\frac{V_{v Z}}{C}+0.04}{\frac{V}{C}-\left[\frac{V}{C}\right]}
$$

where $V_{v Z}$ is the volume of air or gas, $1 / \mathrm{m}^{3} ; C$ - cement consumption per $1 \mathrm{~m}^{3}$ of concrete, $\mathrm{kg} / \mathrm{m}^{3} ;[W / C]$ - the water-cement factor of the test of normal density.

To ensure the design frost resistance of concrete, it is necessary that the actual compensation factor $\Phi_{k}^{a c t i o n}$ be greater than or equal to the standard compensation factor: $\Phi_{k}^{\text {action }} \geq \Phi_{k}^{\text {standart }}$

It is written down the frost resistance conditions of the concrete or

$$
\frac{\frac{V_{v Z}}{C}+0.04}{\frac{V}{C}-\left[\frac{V}{C}\right]} \geq \Phi_{k}^{\text {normat }}
$$

The last value is determined by the formula (17) or from table 7 of GOST 10060-87.

According to the research results, the integral porosity of hyper-compact concrete is $2.3 \%$, i.e., the volume of air pores was $V_{v z}=231 / \mathrm{m}^{3}$. Then the actual compensation factor of concrete with a cement consumption $C=480 \mathrm{~kg} / \mathrm{m}^{3},(V / C)$ rest $=0.29$ equal: $\Phi_{k}^{d e v}=$ $(23 / 480+0.04) /(0.29-0.26)=1.36$

For concrete with a design frost resistance F300 ... 400 fcnorm $=1.2$, (Table 2).

Obviously, $\Phi_{\mathrm{K}}^{\text {effect }}=1.36>\Phi_{k}^{\text {normat }}=1.2$

The frost resistance grade of vibropressed concrete, taking into account $\Phi_{k}^{d e v}=1.36$, is more than 500 (F500).

\section{Conclusions}

1. Obtaining extra-strong concretes of class B100 and higher is possible based on control of the composition of the concrete mixture and concrete, using the developed physical-analytical method for designing concrete compositions and applying the peristaltic method of hyperextension and modification of the concrete mixture.

2. Experimental data have confirmed that the greatest concrete strength is provided at $(\mathrm{W} / \mathrm{C})$ close to the normal density of the cement paste and the use of concrete mixtures with a cement consumption of $10 \ldots 12 \%$ exceeding the minimum binder consumption, which provides optimal conditions for deformation, hypersolidation, and modification mixtures.

3. The choice of the optimal concrete compositions to be hypercompacted and modified is made from the table of equivalent concrete compositions, while the technological parameters of the compositions are obtained in the course of preliminary laboratory experiments.

\section{Funding}

This work is supported by the Russian Science Foundation under grant 21-19-00324. 


\section{References}

1. Khasanov B.B., Punagin VM, Savin,., Shishkin 0.0. The phi- aiko-anapic method of designing concrete warehouses. - Dnipropetrovsk. NVO "Zakhist", p. 156, (1994)

2. Adilkhodjaev, A., Shaumarov, S., Kadir, U. New structure assessment method cell concrete. International Journal of Advanced Science and Technology 29(5), p. 18891893, (2020)

3. Adilhodzhaev A., Shaumarov S., Tsoy V., Khodzhaev S. Research of the influence of silicon-organic hydrophobizer on the basic properties of Cement stone and mortar, International Journal of Advanced Science and Technology, 29(5), pp. 1918-1921, (2020)

4. Shaumarov S.S., Adilhodzhayev A.I., Kondrazhenko V.I. Experimental research of structural organization of heat-insulating structural building materials for energy efficient buildings. XXII International Scientific Conference on Advanced In Civil Engineering «Construction the formation of living environment», pp. 1-7, (2019)

5. Khasanov B. and Mirzaev T., "Production of extra-strong concrete axisymmetric products," in E3S Web of Conferences, 97, (2019), doi: 10.1051 / e3sconf / 20199706011.

6. Bakhridin Khasanov, Nikolai Vatin, Temur Mirzaev, Abdugani Suyunov and Mirzokhid Radjabov, Analysis of the mode of squeezing out excess water for mixing concrete mixture in the process of peristaltic compaction, IOP Conf. Series: Materials Science and Engineering 1030 (2021) 012021 doi:10.1088/1757-899X/1030/1/012021

7. Khasanov B., Irmuhamedova L., Firlina G., Mirzaev T. Theoretical foundations of the structure formation of cement stone and concrete, IOP Conf. Series: Materials Science and Engineering 869, p. 032032, (2020), IOP Publishing doi:10.1088/1757899 X/869/3/032032

8. Khasanov B, Choriev R, Vatin N and Mirzaev T. The extraction of the water-air phase through a single filtration hole. IOP Conf. Series: Materials Science and Engineering 883 (2020) 012206 doi:10.1088/1757-899X/883/1/01220

9. Adilhodzhaev A.I., Shaumarov S.S., Makhamataliev I.M., Tsoy V.M. Features Of Forming The Structure Of Cement Concrete On Second Crushed Stone From Concrete Scrap, International Journal of Advanced Science and Technology, 29,(5), pp. 1901-1906, (2020)

10. Shermuxamedov U.Z., Shaumarov S.S. Impact of configuration errors on the dynamic oscillation absorbers effectiveness of different masses on the seismic resistance of bridges, XXII International Scientific Conference on Advanced in Civil Engineering. Construction the formation of living environment, pp. 1-11, (2019)

11. Khasanov B., Nikolai Vatin, Timur Mirzaev, Abdugani Suyunov and Mirzokhid Radjabov, Physicochemical fundamentals of modifying concrete mix and concrete, IOP Conf. Series: Materials Science and Engineering 1030, (2021) 012022 doi:10.1088/1757-899X/1030/1/012022.

12. B Khasanov, $N$ Vatin, $Z$ Ismailova and $T$ Mirzaev Physical modification of concrete mix and concrete. Materials Science and Engineering 883 012205, (2020) IOP Publishing doi:10.1088/1757-899X/883/1/012205

13. Anvar Adilhodzhaev, Volodya Tsoy, Said Shaumarov, Bunyod Igamberdiev. Influence Of Modified Mineral Fillers With Hydrophobizing Additive On StructuralForming. Solid State Technology, 63 (6). (2020), pp.409 - 413

14. Anvar Adilhodzhaev, Bunyod Igamberdiev, Dilshodkhon Kodirova, Shokhrukh Davlyatov , Akbarjon Marufjonov, Said Shaumarov The Study Of The Interaction Of Adhesive With The Substrate Surface In A New Composite Material Based On 
Modified Gypsum And Treated Rice Straw. Solid State Technology 63(6), (2020), pp.402- 408

15. Belikov V.A., Gushcha KZ.P., Rusanova L.P. and other Influence of water-cement ratio on the properties of concrete, In the book: Prefabricated reinforced concrete structures from high-strength concrete, pp. 28-43, Moscow, 1976.

16. Essorage du beton pan Ie vide Equipment mecanique. Carrieres et Materiaux, № 209, p.29-30; (1983,)

17. Pronning ev betongrors heillfasthet,"Nordiak Betong" 14,(4), 1970.

18. Anvar Adilkhodjaev, Bahriddin Hasanov, Said Shaumarov and Valery Kondrashchenko Aerated concrete with predetermined pore parameters for the exterior walls of energy efficient buildings. IOP Conf. Series: Materials Science and Engineering 1030 (2021), doi:10.1088/1757-899X/1030/1/012006

19. Adilhodzhayev A., Shaumarov S., Shipacheva E., Shermuhamedov U. New method for diagnostic of heat engineering and mechanical properties of cellular concrete // International Journal of Engineering and Advanced Technology (IJEAT), 9(1), pp. 6885-6887, (2019)

20. Adilhodzhayev A. I., Shaumarov S.S., Umarov K.S. New Structure Assessment Method Cell Concrete, International Journal of Advanced Science and Technology 29(5), pp. 1889-1893, (2020)

21. Adilhodzhaev A.I., Makhamataliev I.M., Kadyrov I.A., Shaumarov S.S., Ruzmetov F.S. To the Question of the Influence of the Intensity of Active Centers on the Surface of Mineral Fillers on the Properties of Fine-Grained Concrete. International Journal of Innovative Technology and Exploring Engineering (IJITEE). 8 (9S2), 2019. pp.219-222

22. Kattakulov F., Muslimov T., Khusainov A., Vokhidov O., Sultanov S. Water resource saving in irrigation networks through improving the efficiency of reinforced concrete coatings, IOP Conference Series: Materials Science and Engineering, 883(1), 012053, (2020)

23. Akhverdov I.N. High strength concrete, p. 163, Moscow, (1961)

24. Punagin VN, Savin L, S ,, Khasanov B, B, Shishksh 0,0, Fiaiko-analytical method of designing concrete, - Dnipropetrovsk. NVO "Zakhist", p. 156, (1994)

25. Recommendations for the design of heavy (conventional) concrete, Tashkent Gosstroy UzSSR, p. 62, (1982)

26. Rybakov V., Jos V., Raimova I., and Kudryavtsev K. Modal analysis of frameless arches made of thin-walled steel profiles. IOP Conf. Ser. Mater. Sci. Eng. 883, (2020). 